\title{
ECONOMIC EVALUATION OF THE EFFECT OF ENVIRONMENTAL VARIABLES ON THE PRODUCTION OF MAIZE CROP
}

(Received: 13.7. 2008)

\author{
By \\ M. S. Mashal , S. K. Atta , M. A. Gad* and R. F. Mahmoud* \\ Department of Agricultural Economics, Faculty of Agriculture, Cairo University, Giza, Egypt. \\ *Department of Agricultural Economics, Agricultural Reseach Center, Giza, Egypt.
}

\begin{abstract}
The present study aimed to predict the expected production of summer maize crop under suitable and unsuitable environmental factors. Also, to estimate the expected effect of the environmental factors on the production technique of summer maize crop that reflects the amount of loss in yield due to the unsuitable environmental factors. The study showed the environmental and agricultural requirements of the crop. Also, the study revealed the nature of variance in the Egyptian agricultural environment.

The study showed that the total production of summer maize yield under the appropriate environmental factors ranges from 4272 to 4357 thousand Ardab (Ardab $=140 \mathrm{~kg}$.) with an average of 4315 thousand and with a value of 5084 to 5184 million LE with an average of 5134 million LE under the unsuitable environmental factors, the total production of summer maize yield is expected to be 4153 to 4251 thousand with an average of 4202 thousand and with a value of 4943 to 5059 million LE with an average of 5001 million LE.

Faddan productivity under suitable environmental variables is expected to be 24.57 to 25.05 ard with an average of $24.81 \mathrm{ard} / \mathrm{fed}$ under the unsuitable environmental factors, the productivity is expected to be 23.89 to 24.45 ard with average of 24.17 ard/fed.

The study indicated that the maize crop has low sensitivity to the effect of agricultural and environmental variables in its production regions. This is reflected in the reduction of maize production due to unsuitable environmental variables where the loss amount of the production is $2.8 \%$ of the expected production.
\end{abstract}

Key words: linear programming, production indicators, the environment.

$$
\begin{aligned}
& \text { التقييم الإقتصادى لأثر المتغيرات البيئية على إنتاج محصول الذرة الثامية } \\
& \text { محمد سالم مشعل ـ سهرة خليل عطا ـ محمود عبدالحليم جاد* ـ رانيا فكرى محمود* } \\
& \text { قسم الإقتصاد الزراعى ـ كلية الزراعة ـ جامعة القاهرة ـ الجيزة ـ مصر الإحر }
\end{aligned}
$$

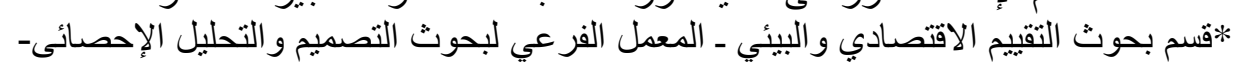

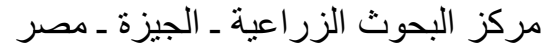

$$
\begin{aligned}
& \text { ملخص متصن }
\end{aligned}
$$

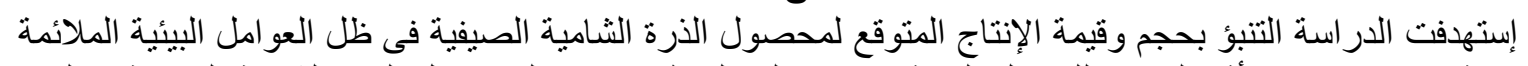

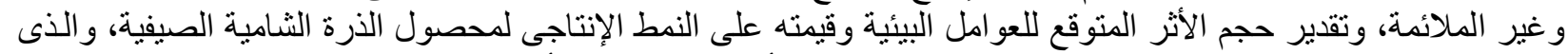

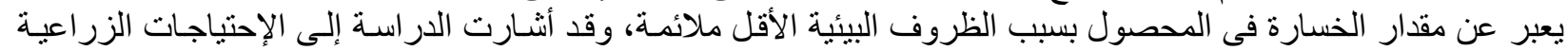

$$
\begin{aligned}
& \text { و البيئية للمحصول و إبراز طبيعة التباين فى البيئة الزر اعية البئة المصرية. }
\end{aligned}
$$

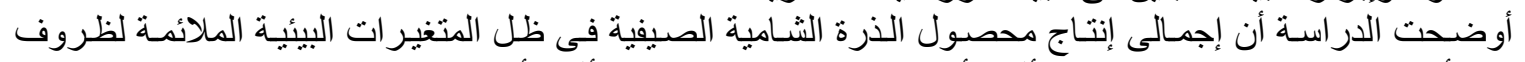

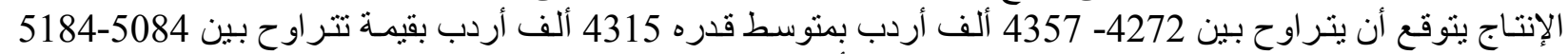

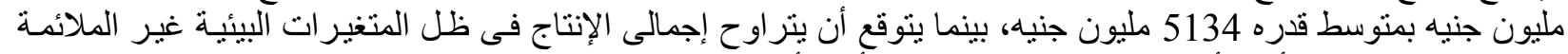

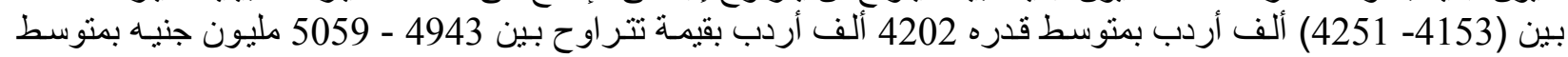

$$
\begin{aligned}
& \text { قدره } 5001 \text { مليون جنيه. }
\end{aligned}
$$




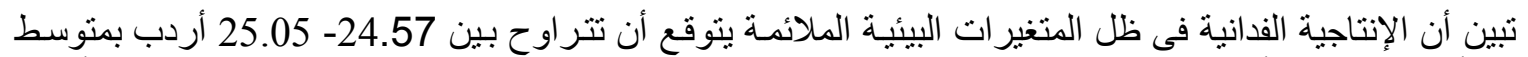

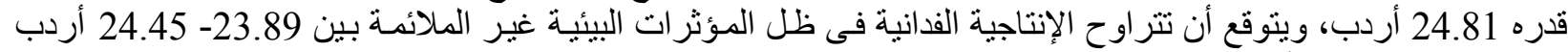
بمتوسط قدره 24.17 أردب.

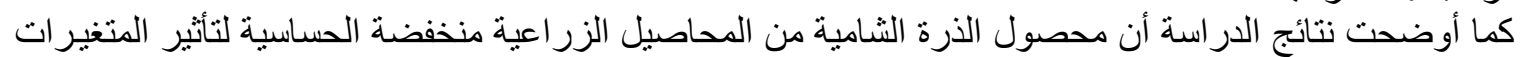

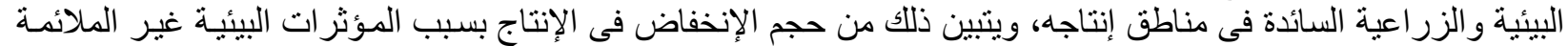
حيث يقدر حجم الفاقد فى الإنتاج بفعل الظروف البئنة اليئية السيئة بنحو 2.8\% من حجم الإنتاج المنوقع.

يتطلب الأمر إعادة النظر فى المنوال الإنتاجى الر اهن بمـا

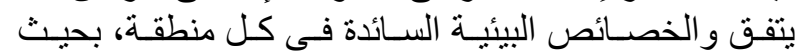

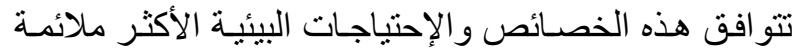
للمحصول.

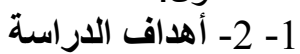

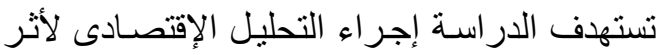

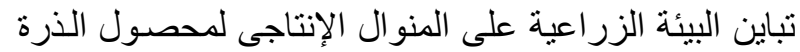

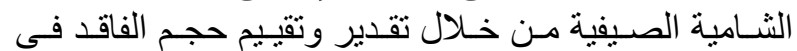

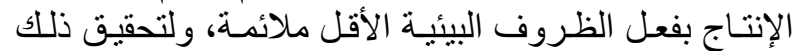
يكون من الضرورى تحديد عدة أهداف رئيسية تتمثل فيما لالخيا

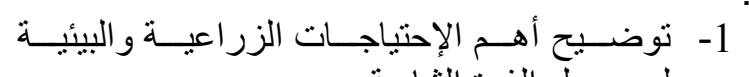

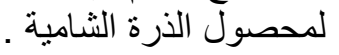

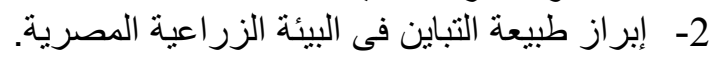

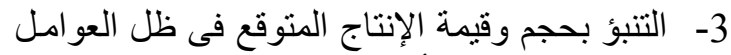
البيئية الملائمة والأقل ملائية

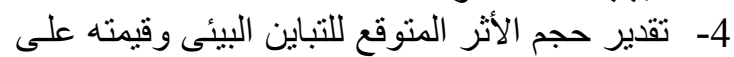
المنو ال الإنتاجى للمحصول. 2-الطريقة البحثية ومصادر البيانات البحنية

تم استخدام أسلوب البرمجة البحئة الرياضية الخطية متعددة البيان

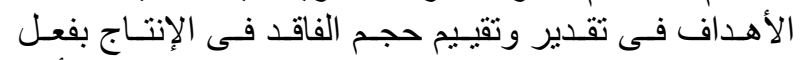

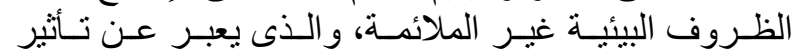

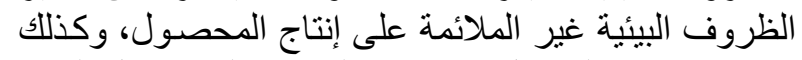

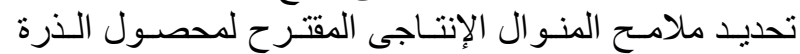

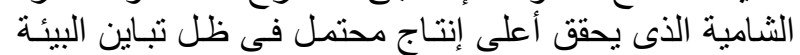

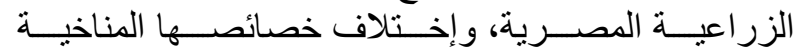

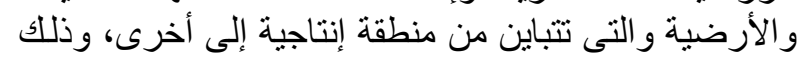

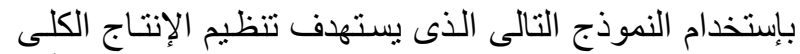

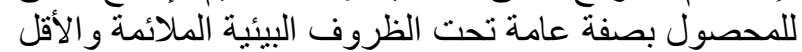

ملائمة.

1-2-البرمجة الرياضية الخطية البرمجة الخطية هي عبارة عن طبية الخريقة أو أسلوب

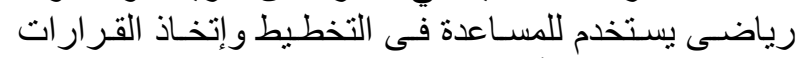

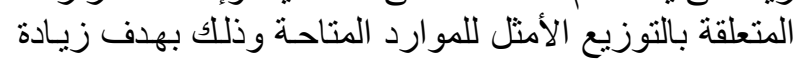

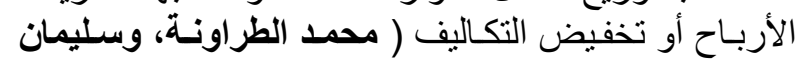

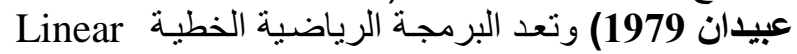

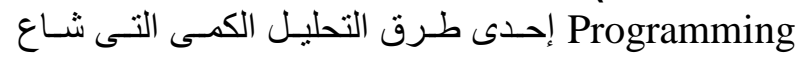

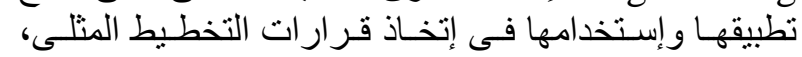

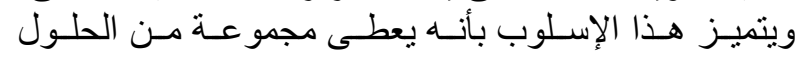

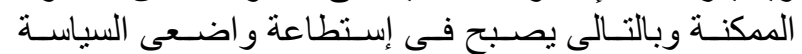

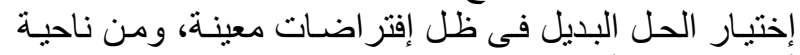

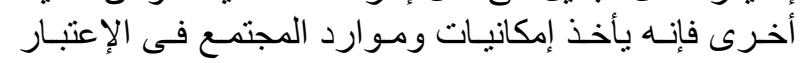
بصورة مباشرة، كما يمتاز بإعطاء إطار منظم للمقارنة بين الإعنار

\section{1 - 1 - 1 مقدمة}

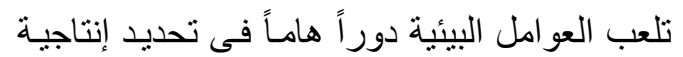

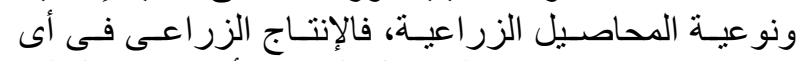

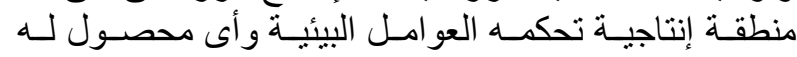

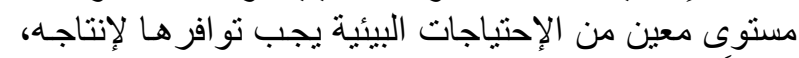

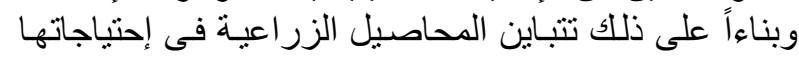

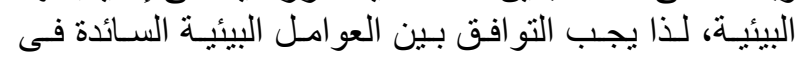

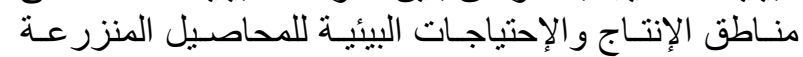

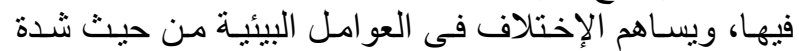

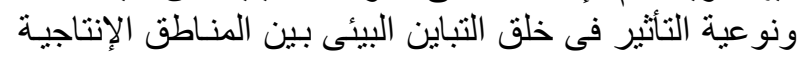

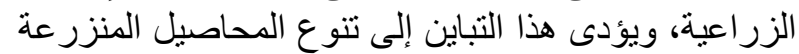

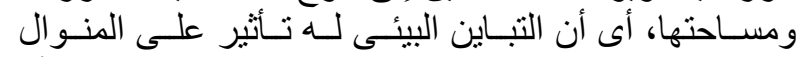

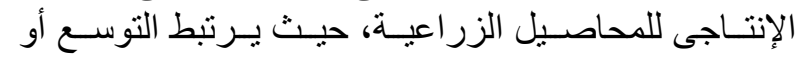

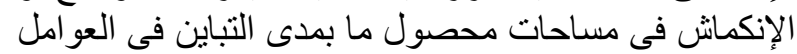
البيئية بين المناطق الإنتاجية.

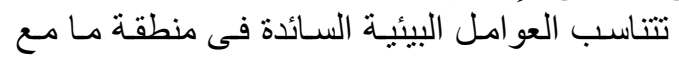

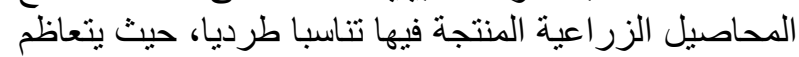

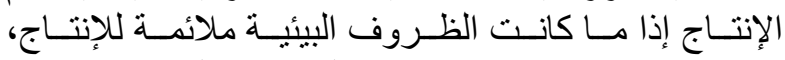

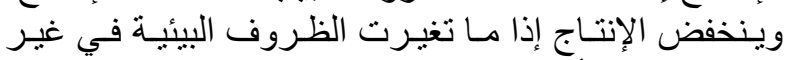

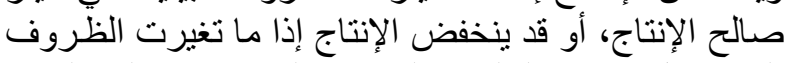

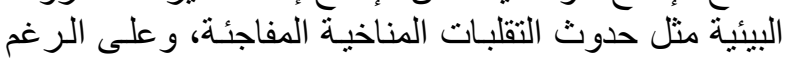

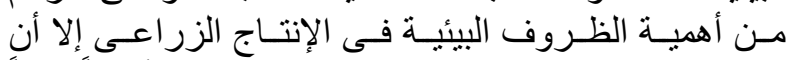

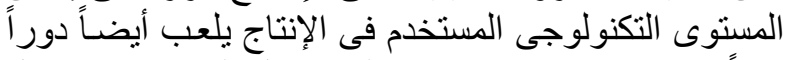

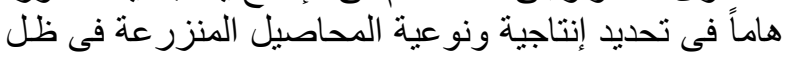

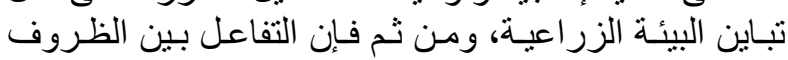

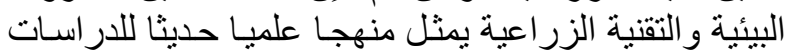

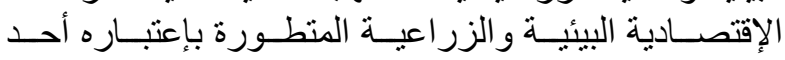

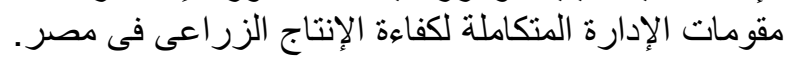
1-1-مشكأة الاراسة

تتسم منـاطق الإنتاج الزراعى في فصى مصر بالتباين

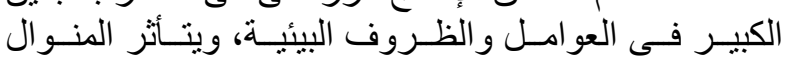

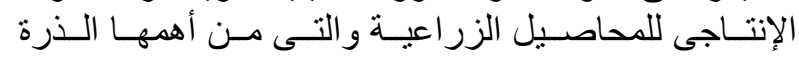

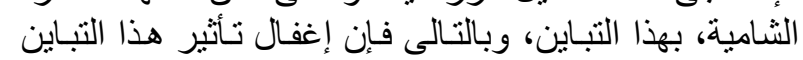

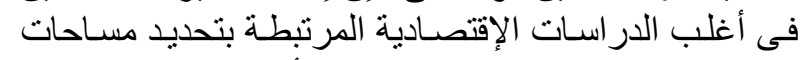

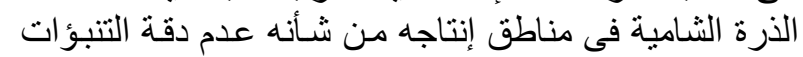

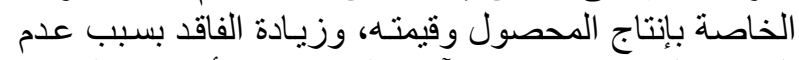

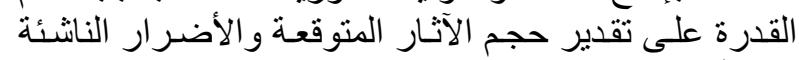

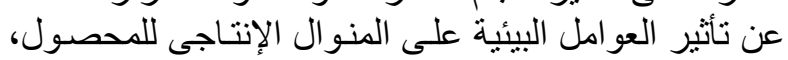

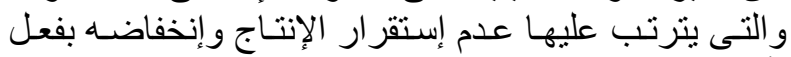

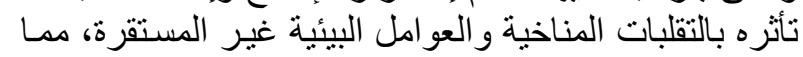

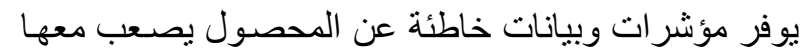
التخطيط لإنتاجه بصورة تفى بإحتباجات الدولة منه، لذللك لكئل 
= اجمالي الإنتاج من المحصول في ظل المتغيرات البيئية

1-2-2-الفروض الأساسية للنموذج الأنج

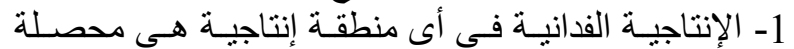

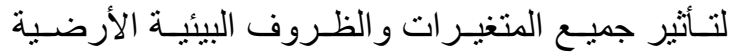

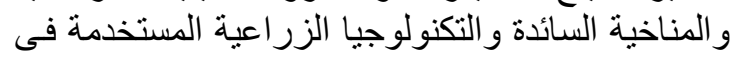
هذه المنطقة

2- عدم ثبات المتغيرات والمؤثرات البيئية داخل المنطقة الإنتاجية الواحدة .

3- التباين البيئى بين المناطق الإنتاجية المختلفة.

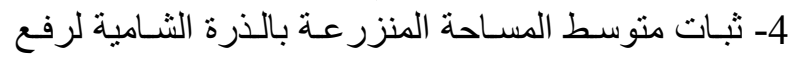
الكفاءة الإنتاجية من ذات المساحة الحالية.

5- ثبات المستوى التكنولوجى السائد فى كل منطقة إنتاجية

إسـتخدمت الدراسـة أيضـاً بعض الأسـاليب الإحصـائية

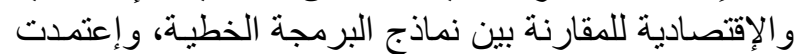

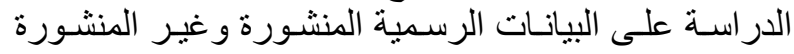

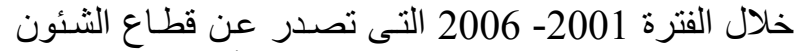

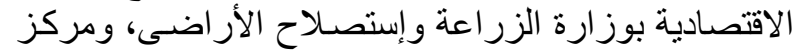

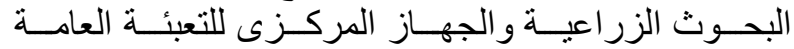

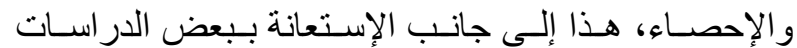

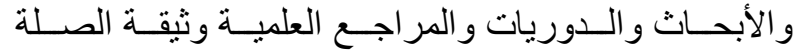

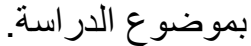

3-2-2الإحتياجات الزراعية لمحصول الذرة الثامية

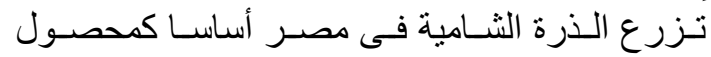

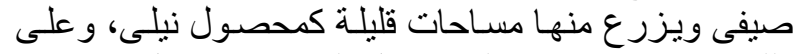

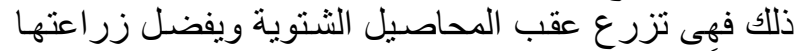

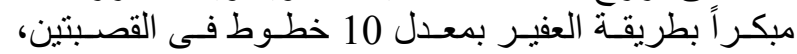

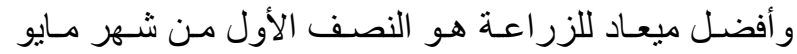

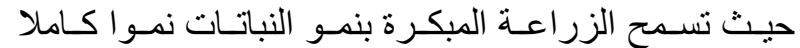

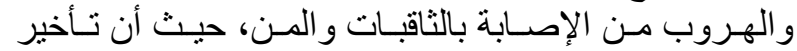

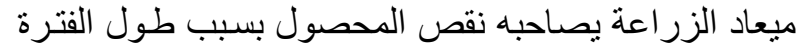

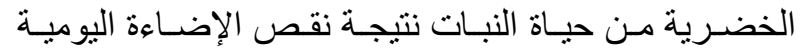

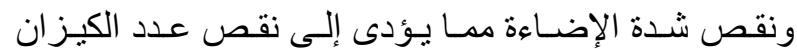

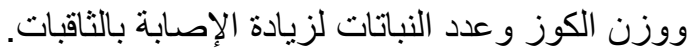

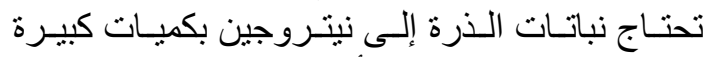

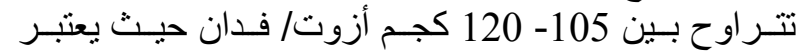

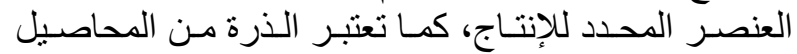

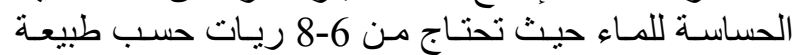

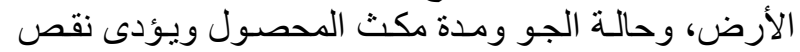

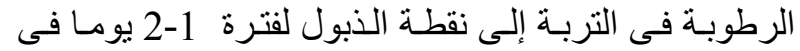

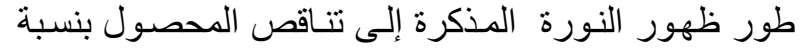

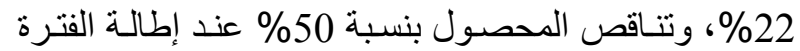

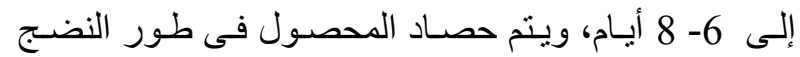

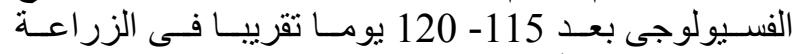

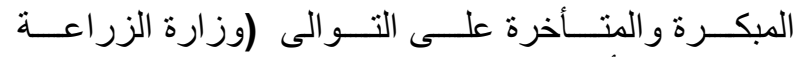
و إستصلاح الأر اضى 2002).

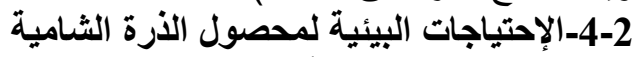

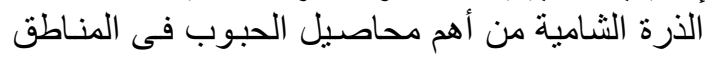

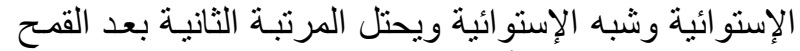

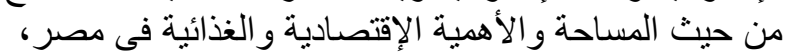

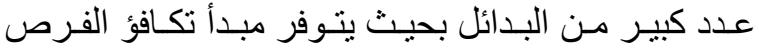

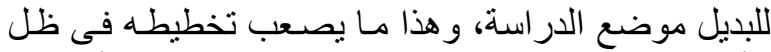

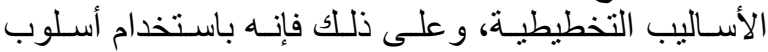

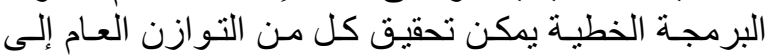

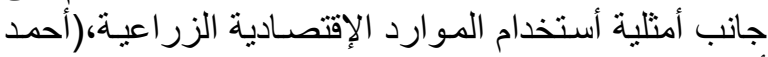

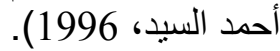

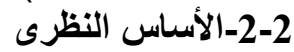

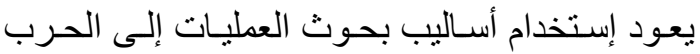

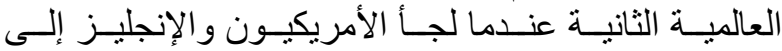

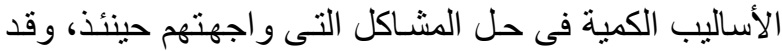

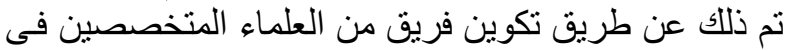

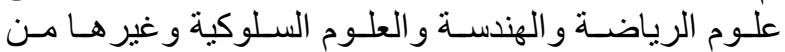

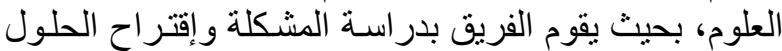
المناسبة مستخدما الأسلوب العلمى في ذلى ذلك.

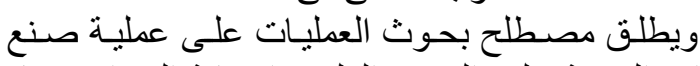

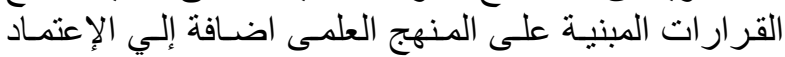

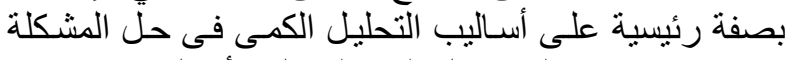

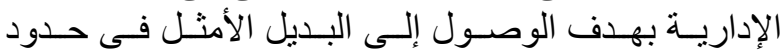

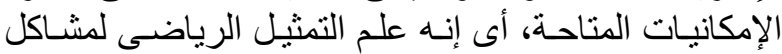

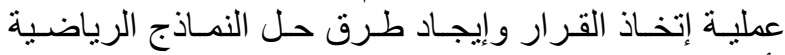
(أسماء محمد باهز موز 1994). وتسعى البرمجة الرياضية إلى تدنية أو تعظيم هدف

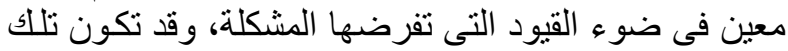

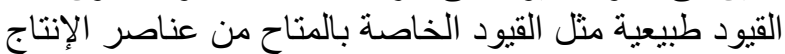

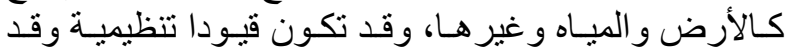

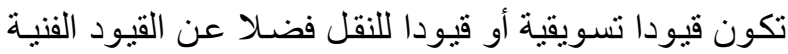

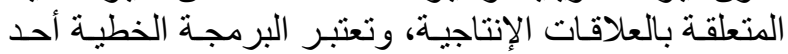

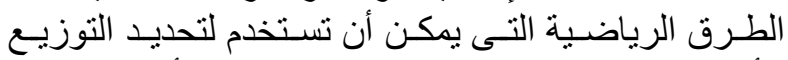

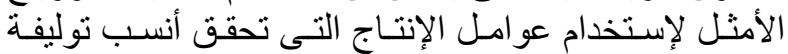

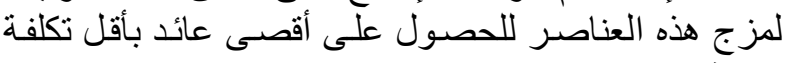
ممكنة.

MAX :(Peter et al., 1986), النموذج الرياضى

\section{Such that}

$$
\begin{array}{lll}
\sum_{j} C_{j t} X_{j} \geq M & \text {, all } & \boldsymbol{t} \\
\sum_{i} a_{i j} X_{j} \leq b_{i} & \text {, all } & \boldsymbol{i} \\
\sum_{j} \bar{C}_{j} X_{j}=\lambda & \text {, all } & \boldsymbol{j} \\
X_{j}, M \geq 0 & &
\end{array}
$$

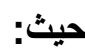

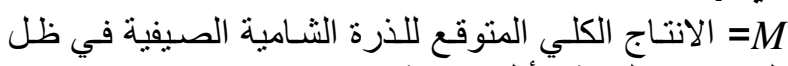

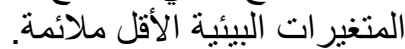
=C المحافظة ز في السنة

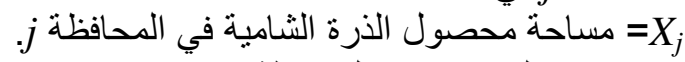
a $=a_{i j}$ = $=b_{i}$

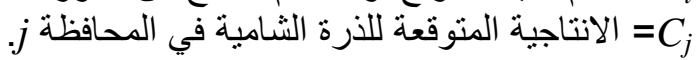




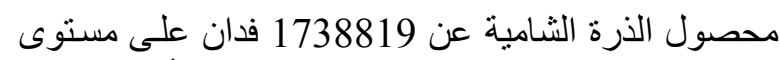
الجمهورية، وينعلق النوع الثانى بقيود الحد الأعلى والحيد فئد

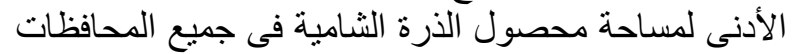

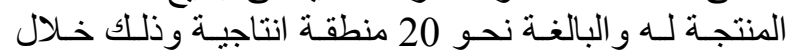
الفترة 2001- 2006. 2-2-5-2 - قيود الموارد المائية الزراعيـة: بعمل هذا القيد

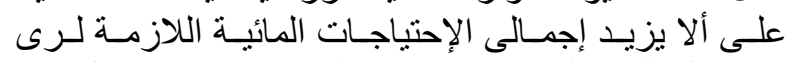

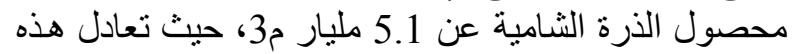

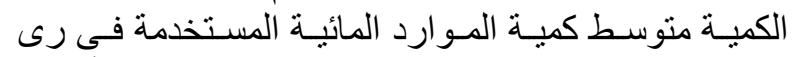

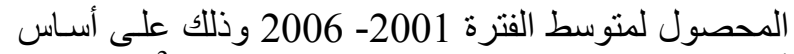

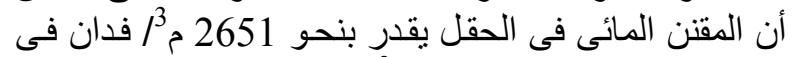

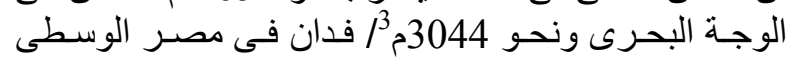

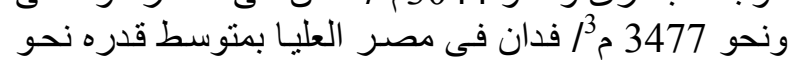
3057 م²/ فدان على مستوى الجمهورية.

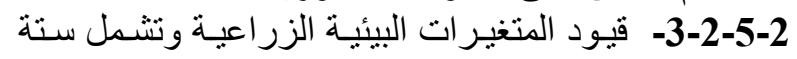

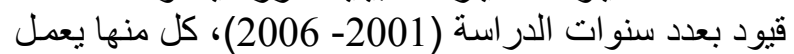

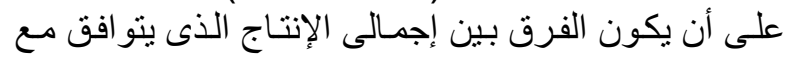

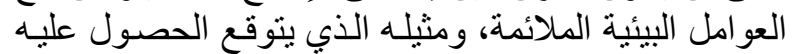

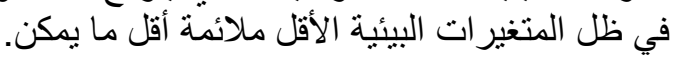

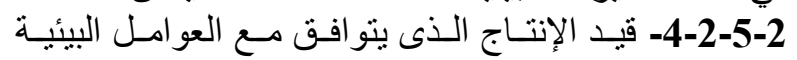

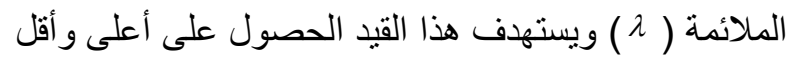

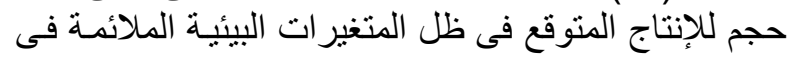

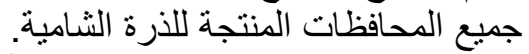

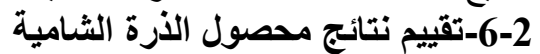

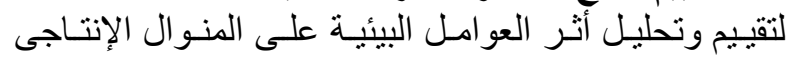

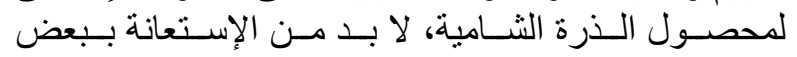

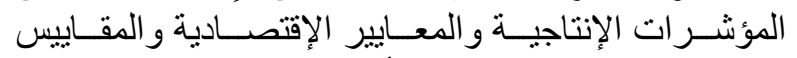

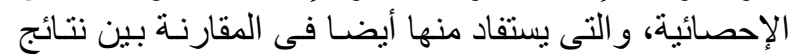

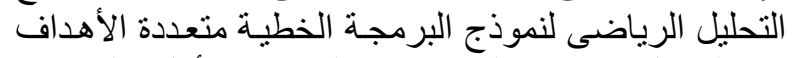
بين المنو ال الإنتاجى المقترح من البرنـامج الأول و البرنـامج

1-6-2-2 المؤشرات الإنتاجية والإقتصادية

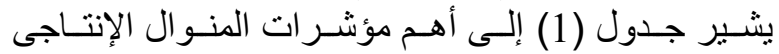

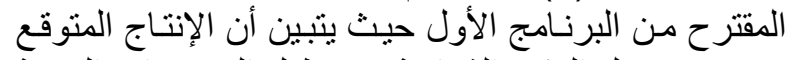

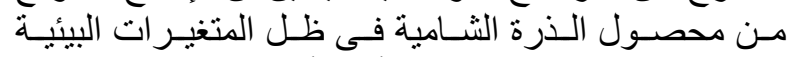

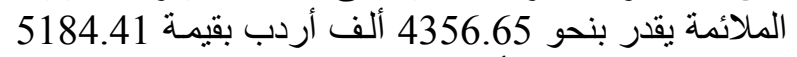

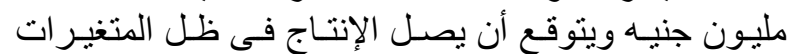

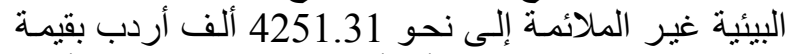

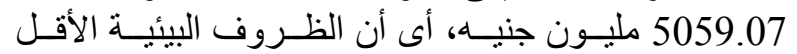

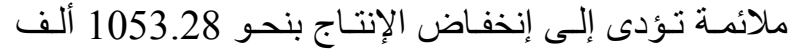

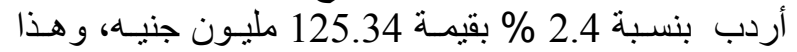

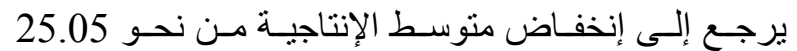

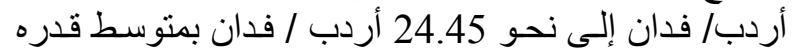

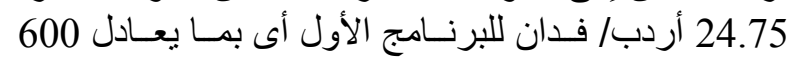

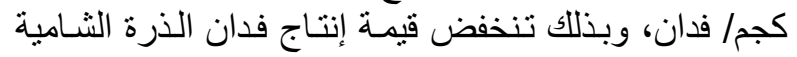

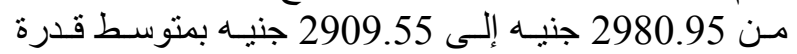
2945 جنيه/ فدان للبرنامج الأول أى بما

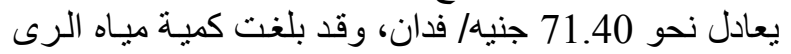
المتاحة للنموذج نحو 5.1 مليار منر مكعب، نم إستنفـاذ

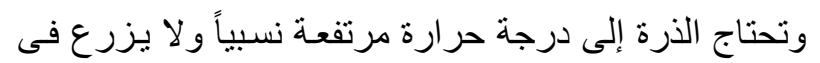

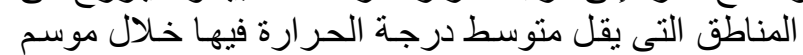

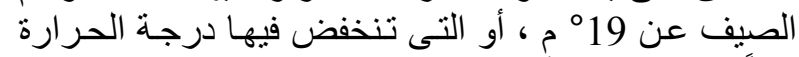

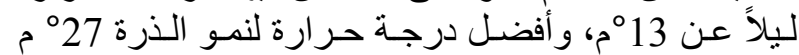

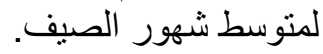

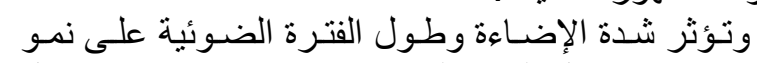

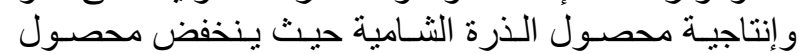

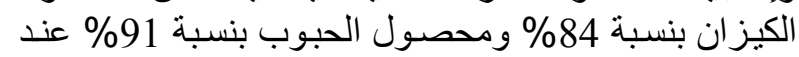

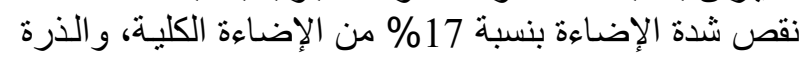

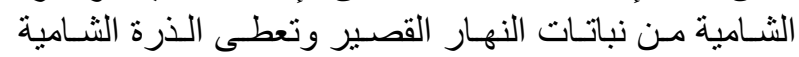

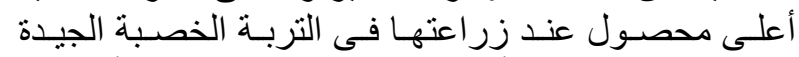

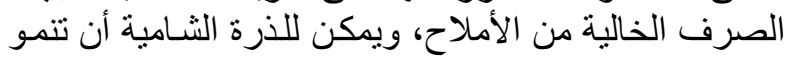

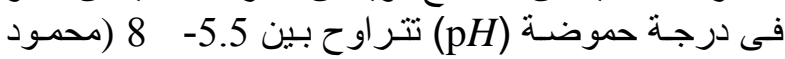

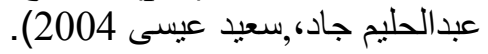

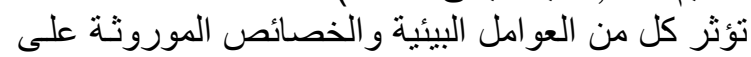

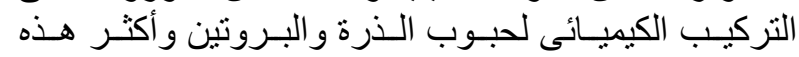

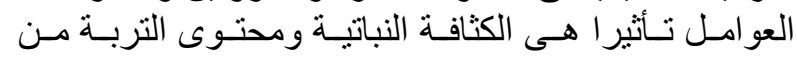

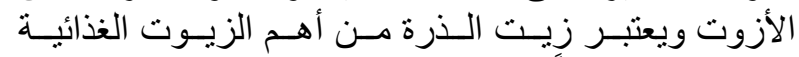

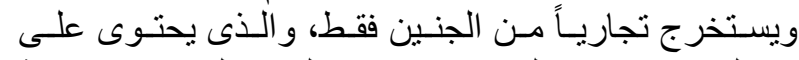

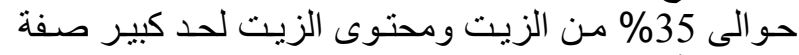

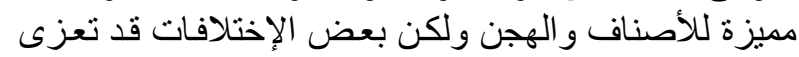

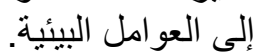

5-2-البرامج المقترحسة لأسـلوب البرمجـة الخطيـة متعددة الأهداف:

تم إعداد برنـامجين للنموذج الرياضسى متعدد الأهداف، الافئ

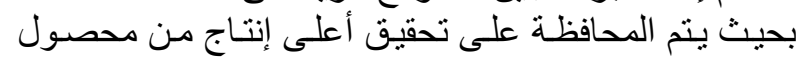

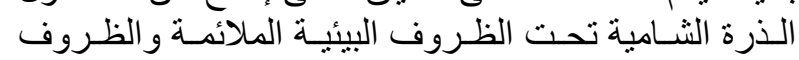

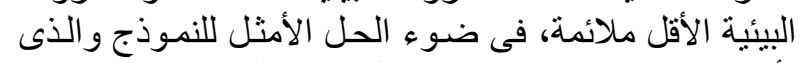

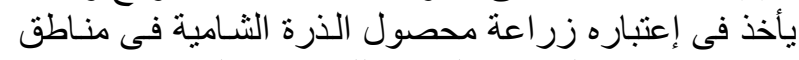

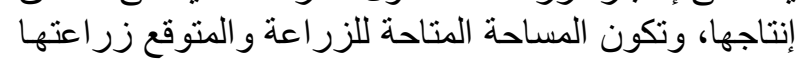

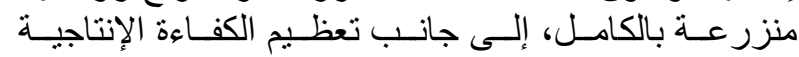

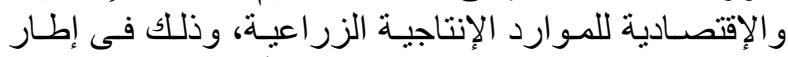

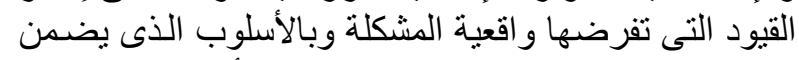

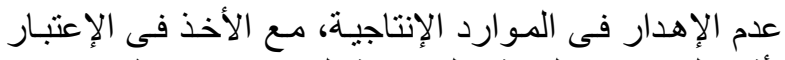

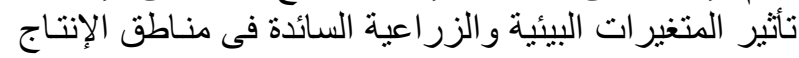
المختلفة والتقلبات البيئية الحادثة فيها.

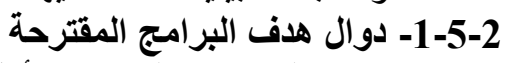

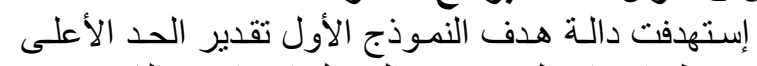

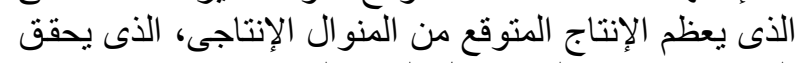

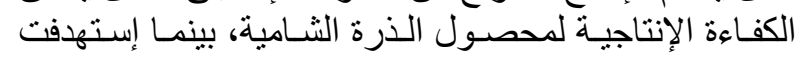

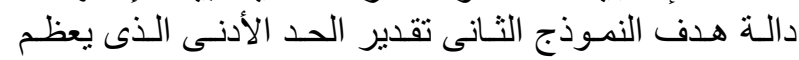

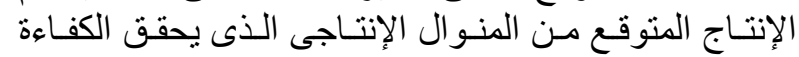

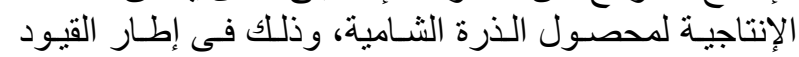

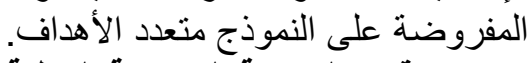
2-5-2-2 قيود البرمجة الرياضية الخطية إنتملت فيود نموذج البردة الرياضة الرياضية الخطية الخطية متعددة الأهداف على ما يلى إنى

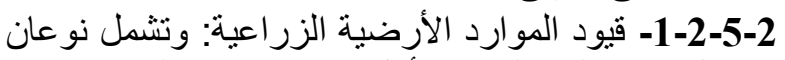

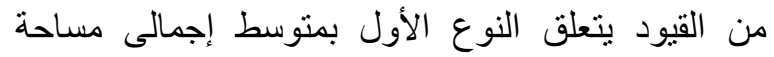

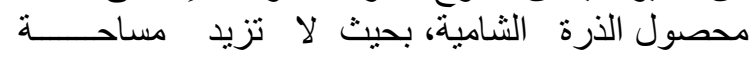




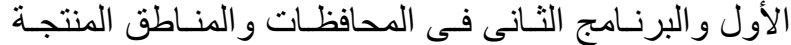

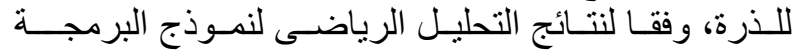

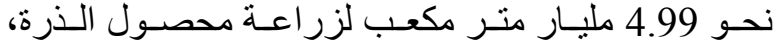

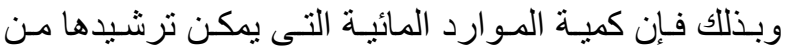

جدول (1): أهم المؤشرات الإنتاجية والإقتصادية لمحصول الذرة الثامية المقترح من نموذج البرمجة الخطية

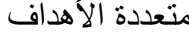

\begin{tabular}{|c|c|c|}
\hline البرنامج الثانى & البرنامج الأول & 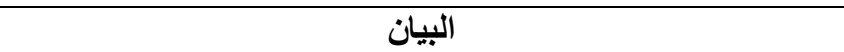 \\
\hline 42722090 & 43566452 & الإنتاج المنوقع فى ظل العو امل البيئية الملائمة بالأردب ( a ) \\
\hline 41534260 & 42513170 & الإنتاج المنوقع فى العو امل البيئية الأقل ملائمة بالأردب (M) \\
\hline 11878000 & 1053282 & تأثتِير العو امل البيئية على الإنتاج المنوقع بالأردب ( M \\
\hline 2.8 & 2.4 & تأثير العوامل البيئية على الإنتاج المتوقع (\%) \\
\hline 42128160 & 43039811 & المتوسط العام للإنتاج المنوقع بالأردب \\
\hline 24.57 & 25.05 & منوسط الإنتاجية فى ظل العو امل البيئية الملائمة بالأردب/ فدان \\
\hline 23.89 & 24.45 & متوسط الإِتناجية فى ظل العو امل البيئية الأقل ملائية بالأردب/ فدان \\
\hline 5083.93 & 5184.41 & قيمة الإنتاج المنوقع فى ظل العو امل البيئية الملائمة بالمليون جنيه \\
\hline 4942.58 & 5059.07 & قيمة الإنتاج المتوقع فى العو امل البيئية الأقل ملائمة \\
\hline 141.35 & 125.34 & تأثير العو امل البيئية على قيمة الإنتاج المتوقع بالمليون جنيه \\
\hline 5013.255 & 5121.74 & المتوسط العام لقيمة الإنتاج المتوقع بآلمليون جنيه \\
\hline 2923.83 & 2980.95 & متوسط قيمة إنتاج الفدان فى ظل آلعو امل البيئية الملائمة بالجنيه \\
\hline 2842.91 & 2909.55 & متوسط قيمة إنتاج الفدان فى ظل العو امل البيئية الأقل ملائمة بالجنيه \\
\hline 5100 & 5100 & كمية الموارد المائية بالمليون متر مكعب \\
\hline 5068.92 & 4996.05 & كمية الموارد المائية المستخدمة بالمليون متر مكعب \\
\hline 31.08 & 103.95 & كمية الموارد التى يمكن ترشيدها بالمليون متر مكعب \\
\hline 0.61 & 2.08 & النسبة المئوية لكمية الموارد المائية التى يمكن ترشيدها \\
\hline 2915 & 2873 & المنوسط العام للمقنن المائى بالمتر الككب/ فدان \\
\hline 2915 & 36182 & المساحةالتى يمكن التوسع فيها باستخدام المو ارد المائية المنوفرة بالفدان \\
\hline
\end{tabular}

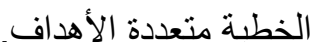

-1-2-6-2-المنوال الإنتاجى المقترح من البرنامج الأول

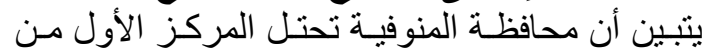

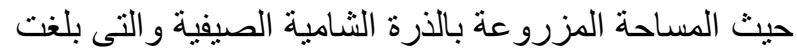
نحو 255.32 ألف فدان بنسبة 14.68\% من الجمالفة الجمالى مساحة الذرة فى مصر، يليها في المرتبة الثانية محافظة المنية المبا بنحو 237.60 ألف فدان بنسبة 13.66\%، يليها في المرتبة الثالثة

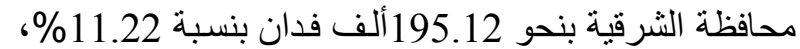
يليها فى المرنبة الرابعة محافظة البحيرة بنحو 172.81 ألف أف

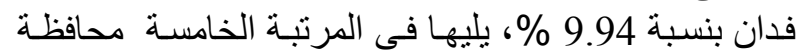

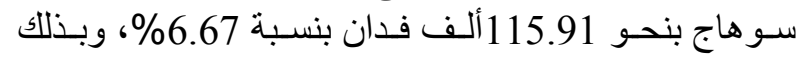

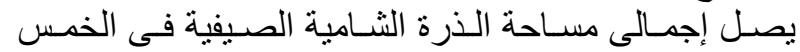

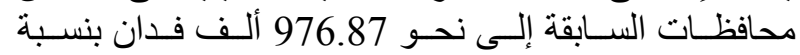

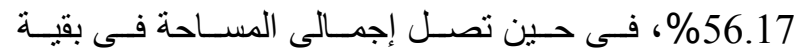

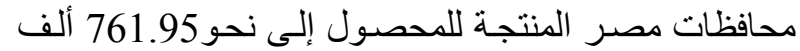

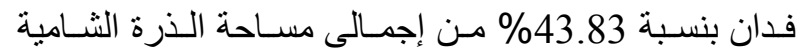
الصيفية بالجمهورية. -2-2-6-2-المنوال الإنتاجى المقترح من البرنامج الثانى

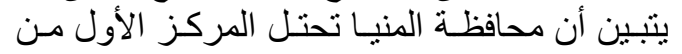

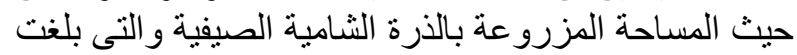

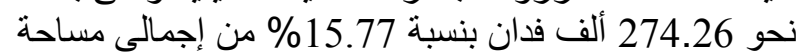

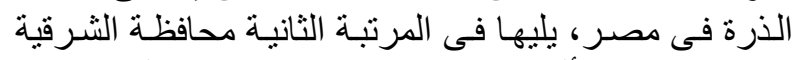

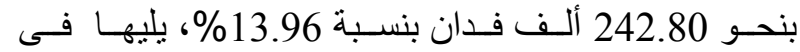
المرتبة الثالثة محافظة المنوفية بنحو 211.50 ألف لنف
النموذج تقدر بنحو 103.95 مليون منر مكعب و هذه الكميـة تكفى لزر اعة نحو 36 ألف فدان إضافية من الذرة الذبر الثامية.

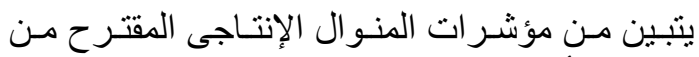

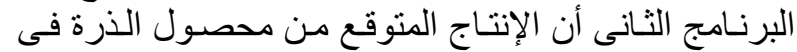

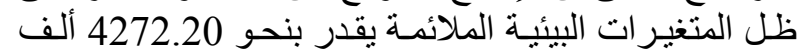

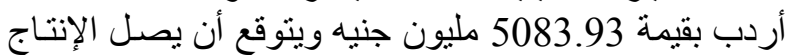
فى ظل المتغيرات البيئية الأقل ملائمـة إلى نحو 4153.43

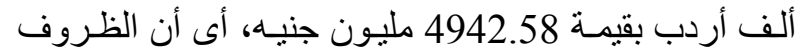

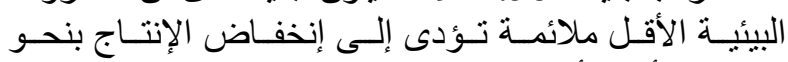

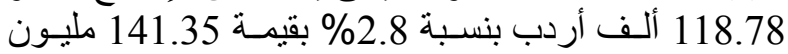
جنيه، و وذذا يرجع إلى إنخفاض منوسط الإنتاجيـة من نحو إنى

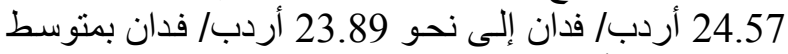

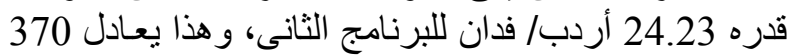

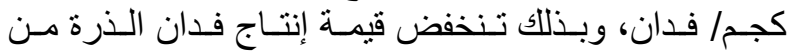

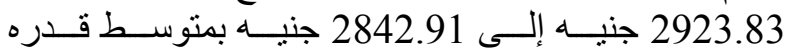

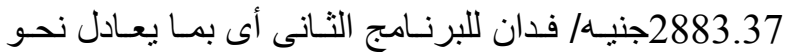

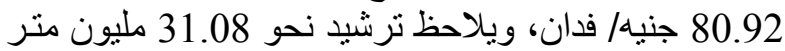

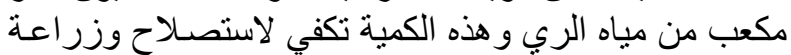
2915 فدان إضافية من الذرة الثامية الصيفية الصية.

2-6-2-2 المسـاحات المقترحة من نموذج البرمجة الخطية الخية متعددة الأهداف

يشير جدول (2) إلى المساحات المقترحة للمنو ال

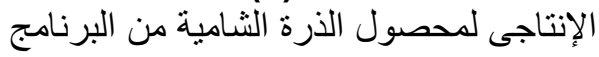


M. S. Mashal et al.,..........................................................................................

جدول (2): المنوال الإنتاجى لمحصول الذرة الثامية الصيفية المقترح من نموذج البرمجة الخطية متعددة الأهداف لأهم

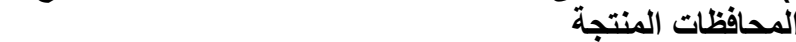

\begin{tabular}{|c|c|c|c|c|}
\hline$\%$ & المساحة بالفدان الثانى & $\%$ & المسناحة بالفدان الأول & المحافظة \\
\hline 1.59 & 27641 & 1.02 & 17709 & الإسكندرية \\
\hline 1.59 & 27701 & 3.49 & 60764 & النوبارية \\
\hline 6.45 & 112297 & 9.94 & 172814 & البحيرة \\
\hline 2.89 & 50232 & 5.47 & 95030 & الغربية \\
\hline 2.40 & 4177 & 3.53 & 61331 & كفر الشيخ \\
\hline 2.60 & 45279 & 4.02 & 69831 & الدقهلية \\
\hline 13.96 & 242795 & 11.22 & 195123 & الشرقية \\
\hline 3.17 & 55106 & 1.80 & 32192 & الإسمـاعيلية \\
\hline 12.16 & 211496 & 14.68 & 255321 & المنوفية \\
\hline 5.03 & 87521 & 3.79 & 65934 & القليوبية \\
\hline 3.32 & 57730 & 3.96 & 68920 & الجيزة \\
\hline 7.18 & 124879 & 5.97 & 103874 & بنى سويف \\
\hline 3.07 & 53459 & 2.12 & 36838 & الفيوم \\
\hline 15.77 & 274255 & 13.66 & 237604 & المنيا \\
\hline 6.53 & 113597 & 4.98 & 86566 & أسيوط \\
\hline 7.09 & 123346 & 6.67 & 115906 & سوهاج \\
\hline 2.8 & 49546 & 1.89 & 32836 & قنا \\
\hline 0.67 & 11729 & 0.45 & 7730 & أسوان \\
\hline 0.74 & 12812 & 0.59 & 10271 & الأقصر \\
\hline 0.90 & 15628 & 0.70 & 12225 & أخرى \\
\hline 100 & 1738819 & 100 & 1738819 & الإجمالى \\
\hline
\end{tabular}

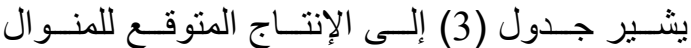

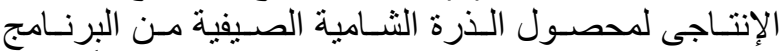

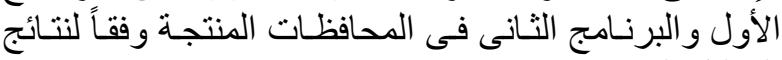

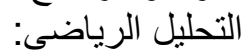

1-3-6-2 الإنتاج المتوقع من البرنامج الأول المئل

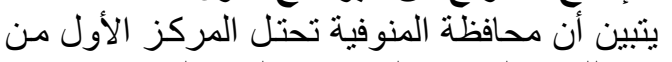

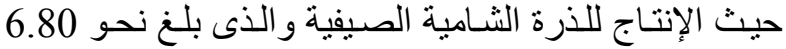

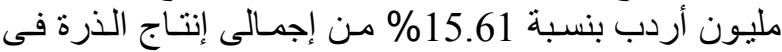
مصر، يليهـا في المرتبـة الثانيـة محافظـة المنيـا بنحو 5.86.

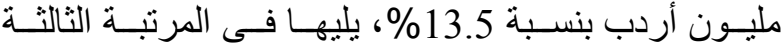

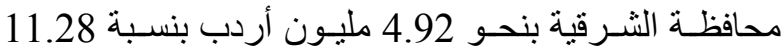

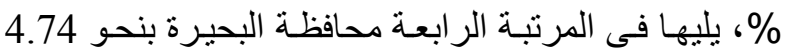

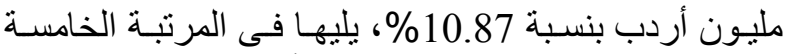

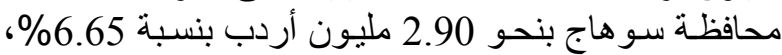

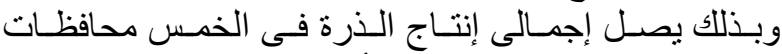

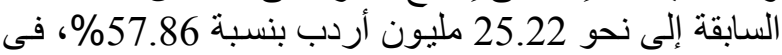
حين يصل إجمالى الإنتاج فى بقية محافظـات مصر المدية المنتجة

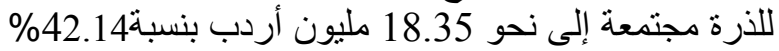
من إجمالى إنتاج الذرة بالجمهورية.

-2-3-6-2

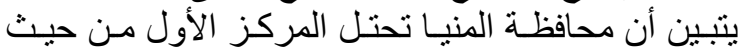

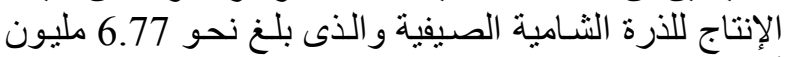

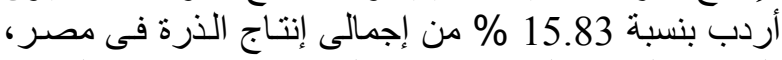
يليها فى المرتبة الثانية محافظة الثرقية بنحو 6.12 مليون الثناج
فدان بنسبة 12.16\%، يليهـا فـى المرتبـة الر ابعـة محافظـة

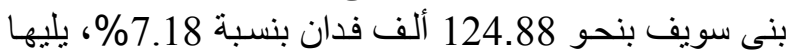

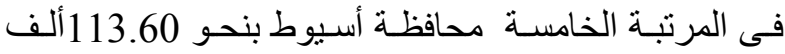

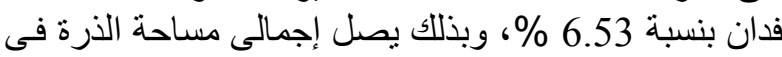
الخمس محافظات السابقة إلى نحو 65 \%

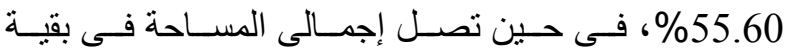

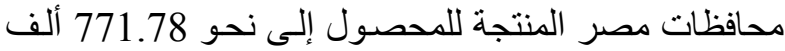
فدان بنسبة 44.40\% مـن إجمـالى مسـاحة الذرة الثــامية الصبفية بالجمهورية.

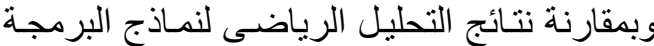

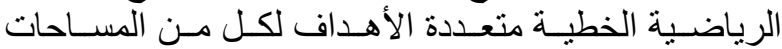

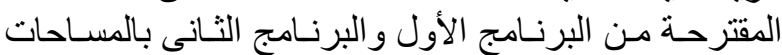

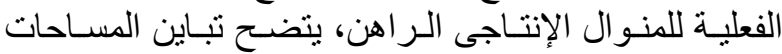

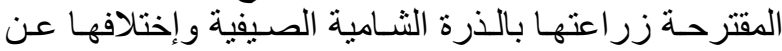

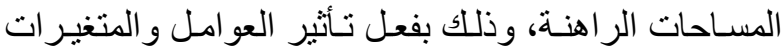

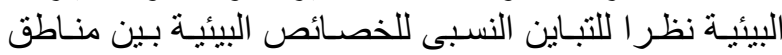

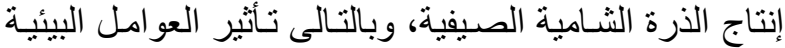

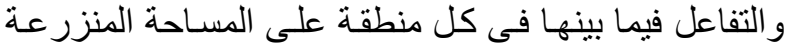

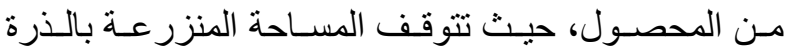

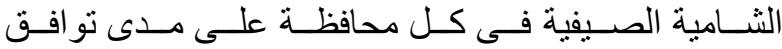

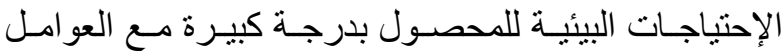

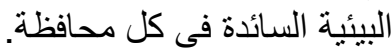

الاملاف -3-6-2 الإنتاج المتوقع من نموذج البرمجة الخطية متعددة

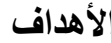


فى حين تعتبر بقية محافظات الجمهوريـة أقل ملائمسة لإنتاج

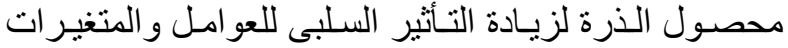
البيئية الطبيعية و الزر اعية الأقل ملائمة.
أردب بنســبة 14.32 \% \% يليهــا فــى المرتبـــة الثالثــة محافظـة المنوفيـة بنـــو 5.63 مليـون أردب بنسـبة 13.19

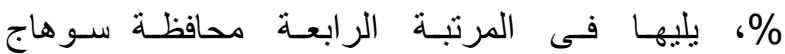

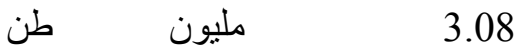
بنحو

جدول (3):الاتتاج المتوقع في ظل المتغيرات البيئية الملائمة لمحصول الذرة الثامية الصيفية بالأردب لأهم المحافظات المنتجة في

\begin{tabular}{|c|c|c|c|c|}
\hline$\%$ & الإنتاج بالإردب الثانى & $\%$ & الإنتاج بالإردب الأول & المحافظة \\
\hline 1.28 & 548674 & 0.80 & 351524 & الإسكندرية \\
\hline 1.70 & 724658 & 3.64 & 1589586 & النوبارية \\
\hline 7.20 & 3076938 & 10.87 & 4735104 & البحيرة \\
\hline 3 & 1282925 & 5.57 & 2427066 & الغزبية \\
\hline 2.49 & 1062629 & 3.58 & 1560261 & كفر الشيخ \\
\hline 2.90 & 1237475 & 4.38 & 1908481 & الدقهلية \\
\hline 14.32 & 6116006 & 11.28 & 4915148 & الشرقية \\
\hline 2.83 & 1210128 & 1.62 & 706936 & الإسماعيلية \\
\hline 13.19 & 5634253 & 15.61 & 6801751 & المنوفية \\
\hline 4.93 & 2105755 & 3.64 & 1586372 & القليوبية \\
\hline 3.76 & 1606049 & 4.40 & 1917354 & الجيزة \\
\hline 6.44 & 2751084 & 5.25 & 2288344 & بنى سويف \\
\hline 2.63 & 1125312 & 1.78 & 775440 & القيوم \\
\hline 15.83 & 6763128 & 13.45 & 5859315 & المنيا \\
\hline 6.37 & 2719512 & 4.76 & 2072390 & أسيوط \\
\hline 7.22 & 3082417 & 6.65 & 2896491 & سوهاج \\
\hline 2.27 & 971102 & 1.48 & 643586 & قنا \\
\hline 0.46 & 198572 & 0.30 & 130869 & أسوان \\
\hline 0.61 & 260084 & 0.48 & 208501 & الأقصر \\
\hline 0.57 & 245360 & 0.44 & 191933 & أخرى \\
\hline 100 & 42722060 & 100 & 43566452 & الإجمالى \\
\hline
\end{tabular}

4-6-2 أربحيـة الفـــان مسن محصــول الـــرة الثــامية الصيفية:

يوضـح جدول (4) أن إجمـالى التكـاليف الإنتاجيـة

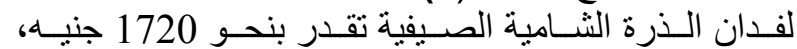

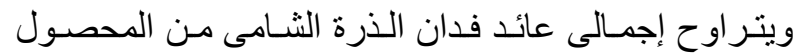

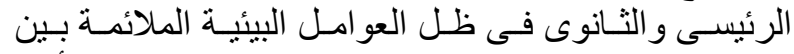

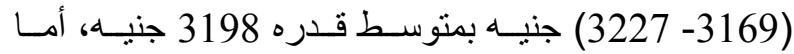

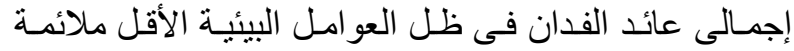

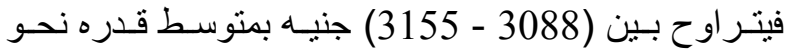

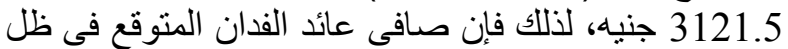

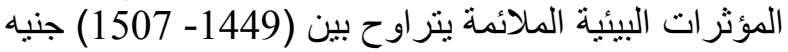

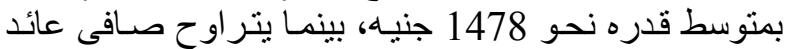
الفدان فى ظل المؤثرات البيئية غير الملائكسة بنحو (1435 (1368-

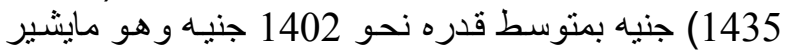

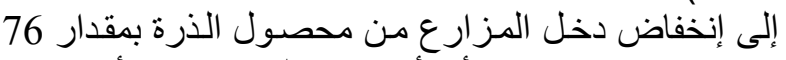

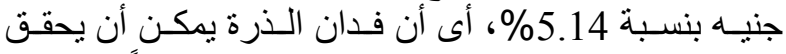

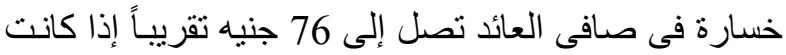

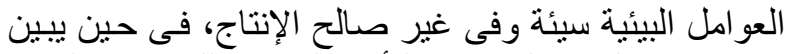

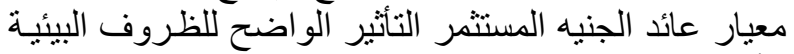

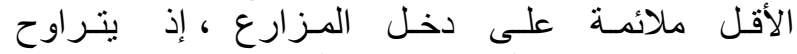

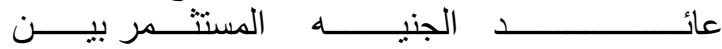

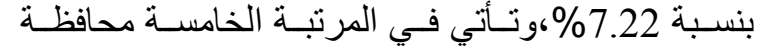

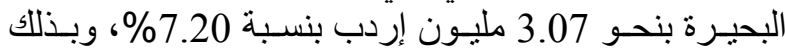
يصل إجمالي الإنتاج في الخمس محافظات السـابقة الي نحو

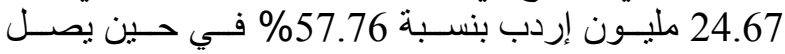

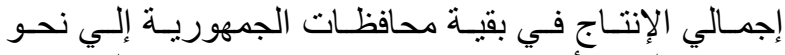
18.05 مليون أردب بنسبة 42.24 \% مـن إجمـالى إنتـاج الذرة الثامية بالجمهورية.

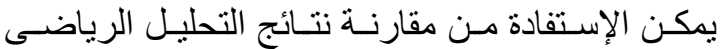

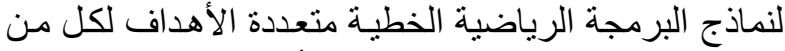

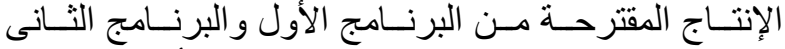

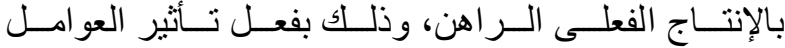

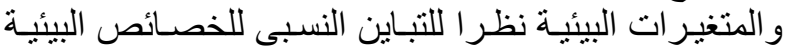

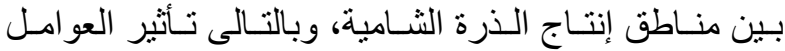

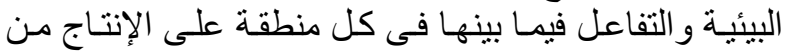

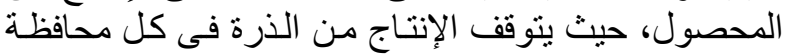

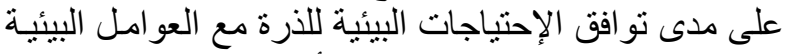

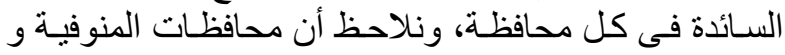

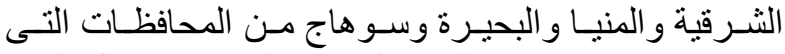

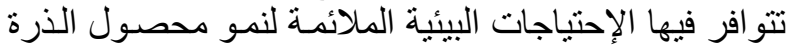

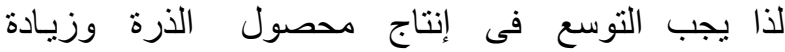

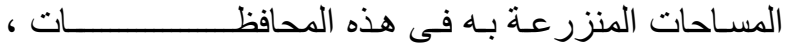




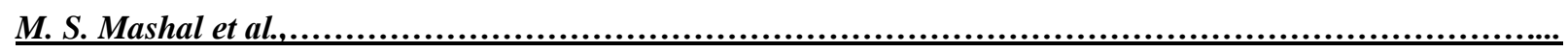

جدول (4): صافى عائد الفدان المتوقع بالجنيه لمحصول الذرة الثامية الصيفية

\begin{tabular}{|c|c|c|c|c|}
\hline \multicolumn{2}{|c|}{ في ظل العوامل البيئية غير الملائمة } & \multicolumn{2}{|c|}{ فى ظل العوامل البيئية الملائمة } & \multirow{2}{*}{ بنود التكاليف } \\
\hline البرنامج الثانى & البرنامج الأول & البرنامج الثانى & البرنامج الأول & \\
\hline 442.71 & 442.71 & 442.71 & 442.71 & أجور العمل البشرى \\
\hline 1.9 & 1.9 & 1.9 & 1.9 & أجور العمل الحيوانى \\
\hline 207 & 207 & 207 & 207 & أجور العمل الألى \\
\hline 117.05 & 117.05 & 117.05 & 117.05 & التقاوى \\
\hline 101.15 & 101.15 & 101.15 & 101.15 & السماد البلاى \\
\hline 217.32 & 217.32 & 217.32 & 217.32 & الأسمدة الكيماوية \\
\hline 30.33 & 30.33 & 30.33 & 30.33 & المبيدات \\
\hline 100.78 & 100.78 & 100.78 & 100.78 & المصاريف العمومية \\
\hline 576.43 & 576.43 & 576.43 & 576.43 & الإيجار \\
\hline 1720 & 1720 & 1720 & 1720 & إجمالى التكاليف \\
\hline 3088 & 3155 & 3169 & 3227 & إجمالى العائد \\
\hline 1368 & 1435 & 1449 & 1507 & صافى العائد المتوقع \\
\hline 1.79 & 1.83 & 1.84 & 1.87 & عائد الجنيه المستثمر \\
\hline
\end{tabular}

أسماء محمد باهر موز (1994). مقدمة فى بحمة بحوث العمليات، دار جدة للطباعة و النشر.

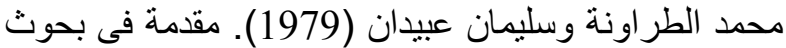
العمليات. أساليب وتطبيقات، كلية الإنية الإنصاد و العلوم

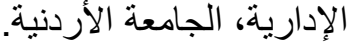

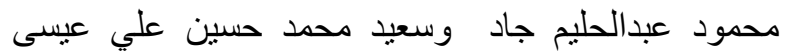

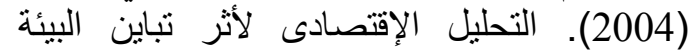

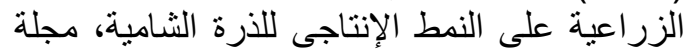

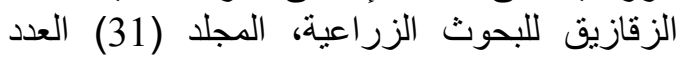

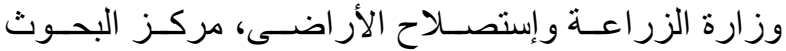

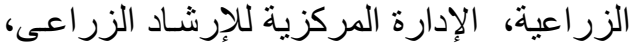
نشرة الذرة الثامية رقم 734، 734 (2002).

Peter B., Hazell P. and Norton R.D. (1986). "Programming for Economic Analysis in Agriculture", MacMillan Publishing, Company, New York.

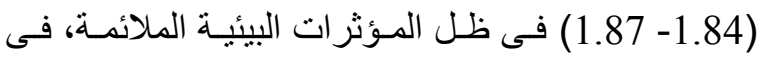
حين يتر اوح عائد الجنيه المستثمر بين (1.79- 1.83 1.83) فى في ظل المؤثرات البيئية الأقل ملائمة.

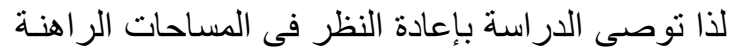

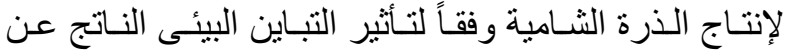

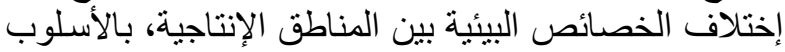

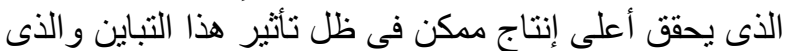

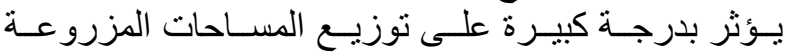
بالمصول والإنتاجية الفدانية السائدة بكل منطقة الكية.

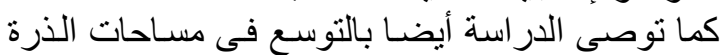

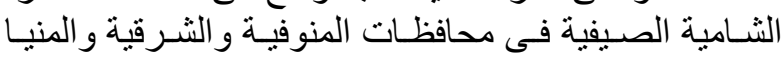

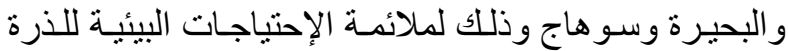

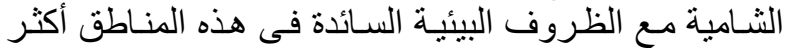
من غير ها من المناطق الانتاجية.

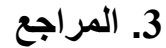

أحمد أحمد السيد (1996). التخطيط الإقتصادى الزراعى الزيع

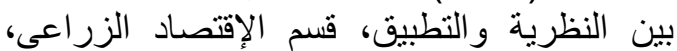
كلية الزر اعة، جامعة قناة السويس. 
